\title{
Habitat use, relative growth and size at maturity of the purple stone crab Platyxanthus crenulatus (Decapoda: Brachyura), calculated under different models
}

\author{
Nahuel E. Farias, Tomas A. Luppi, Eduardo D. Spivak \\ Instituto de Investigaciones Marinas y Costeras, Consejo Nacional de Investigaciones Científicas y Técnicas (CONICET). \\ Facultad de Ciencias Exactas y Naturales, Universidad Nacional de Mar del Plata, CC 1260, Funes 3350,7600 Mar del \\ Plata, Argentina. E-mail: nefarias@mdp.edu.ar (NEF); taluppi@mdp.edu.ar (TAL); espivak@mdp.edu.ar (EDS)
}

\begin{abstract}
Summary: We describe the most noteworthy changes occurring during the post-metamorphic phase in both sexes of the purple stone crab Platyxanthus crenulatus. Spatial structure of the populations by size and early changes in colour pattern and relative growth of chelae suggest an ontogenic migration from intertidal to deeper waters. Before reaching maturity and laying eggs, females undergo a tight sequence of morpho-physiologic changes over a narrow size range (44-64 mm carapace width $[\mathrm{CW}])$. In contrast, males undergo two main phases related to sexual maturity. Early in their lives, they develop sperm and accelerate the relative growth of the chelae $(35-45 \mathrm{~mm} \mathrm{CW})$. Morphologic maturity of males comes later, when relative growth rate reaches the maximum and decelerate $(65-70 \mathrm{~mm} \mathrm{CW})$. Adult males are larger and develop conspicuously largest chelae than females. Morphometric analyses were performed by two different techniques: the traditional procedure, which describes relative growth relationships as power functions; and an alternative, smoothing spline-based model that is nondependent on previous assumptions. The results of the alternative analysis were coherent with other reproductive indicators and ancillary observations, allowing a more comprehensive understanding of the relative growth. We provide supporting material containing the respective script written in $\mathrm{R}$ program to be used freely in future studies.
\end{abstract}

Keywords: sexual maturity; stone crabs; southwestern Atlantic; alternative methods; relative growth.

Uso de hábitat, crecimiento relativo y talla de madurez, calculada mediante diferentes modelos, del cangrejo violeta Platyxanthus crenulatus (Decapoda: Brachyura)

Resumen: Se describen los eventos más remarcables durante la ontogenia de la fase post-metamórfica del cangrejo violeta de las rocas Platyxanthus crenulatus. Las poblaciones estudiadas aparecen estructuradas por talla, lo que sumado a cambios tempranos en el patrón de coloración y en la tasa de crecimiento relativo de las quelas de ambos sexos, sugiere la existencia de una migración ontogénica desde el intermareal hacia aguas más profundas. Antes de alcanzar la madurez y extruir huevos, las hembras atraviesan una serie de cambios morfo-fisiológicos en un rango de tallas estrecho (44-64 mm). En contraste los machos muestran dos fases bien diferenciadas en relación a la madurez sexual. Tempranamente desarrollan esperma y aceleran el crecimiento relativo de las pinzas $(35-45 \mathrm{~mm})$. La madurez morfológica se alcanza posteriormente cuando la tasa de crecimiento relativo alcanza su máximo y comienza a desacelerarse $(65-70 \mathrm{~mm})$. Los machos adultos son más grandes y tienen quelas de mayor tamaño que las de las hembras. Los análisis morfométricos fueron realizados aplicando paralelamente dos técnicas diferentes: el procedimiento tradicional, que describe al crecimiento relativo como una función potencial, y un método alternativo, no dependiente de supuestos a priori, basados en splines. Los resultados del análisis alternativo fueron coherentes con los demás indicadores reproductivos y observaciones auxiliares permitiendo una comprensión más amplia del crecimiento relativo. Se adjuntan los comandos necesarios para aplicar ambos métodos libremente usando el programa R.

Palabras clave: madurez sexual; cangrejos de roca; Atlántico Sudoeste; métodos alternativos; crecimiento relativo.

Citation/Como citar este artículo: Farias N.E., Luppi T.A., Spivak E.D. 2014. Habitat use, relative growth and size at maturity of the purple stone crab Platyxanthus crenulatus (Decapoda: Brachyura), calculated under different models. Sci. Mar. 78(4): 567-578. doi: http://dx.doi.org/10.3989/scimar.04108.10A

Editor: E. Macpherson.

Received: June 5, 2014. Accepted: September 10, 2014. Published: October 15, 2014.

Copyright: (C) 2014 CSIC. This is an open-access article distributed under the Creative Commons Attribution-Non Commercial Lisence (by-nc) Spain 3.0. 


\section{INTRODUCTION}

Life cycles of benthic invertebrates with pelagic larvae may suffer drastic morphological, physiological and behavioural changes at metamorphosis; however, other important changes, although less dramatic, may occur after settlement. Such changes are mostly adaptations to sequential exploitation of different niches during growth and are often accompanied by habitat shifting and, consequently, the spatial structuration of the populations by size (Pardo et al. 2007). The efficient exploitation of ontogenetic niches generally requires different morphologies and colour patterns associated with changing diets (Jensen and Asplen 1998) and predatory risks (Palma and Steneck 2001, Reuschel and Schubart 2007).

A landmark within the post-metamorphic phase is the attainment of sexual maturity, which involves a suite of morphological, physiological and behavioural changes that must occur in harmony for effective reproduction to take place. In crabs sexual maturity is attained progressively through a series of steps. The sequence and synchronicity of these steps are particular to each species (Fernández-Vergaz et al. 2000, Leal et al. 2008) and therefore the size at maturity may vary depending on the particular ontogenic change observed. For most purposes, it is desirable to estimate the sexual maturity based on the direct observation of the size at which individuals are reproducing in nature. However, to do so it is necessary to capture a large number of mating pairs and egg-bearing females, which can be a difficult task in full marine species, given that reproductive individuals tend to hide and/ or migrate to areas of difficult access for researchers. Consequently, estimations of the size at maturity of crabs have been traditionally based on a combination of direct observations of the qualitative traits related to reproduction (hereafter "reproductive indicators") and morphometric analysis (e.g. López-Greco and Rodríguez 1999, Hall et al. 2006, Sal Moyano et al. 2010). Reproductive indicators, such as the morphology of gonads, seminal receptacles and vulvae, have discrete response values (mostly binary as mature/inmature) that are readily observable, so the classification of an individual as mature usually pose no further problems.

In contrast, determining maturity based solely on morphometric traits (hereafter "morphometric indicators") may be rather problematic. The relative growth that leads to an overall mature shape occurs in a continuum during the ontogeny, thus requiring analyses that are methodologically more complicated. Moreover, the potential existence of different morphotypes of mature males (as evidenced by the growing list of species with alternative mating strategies, see Shuster 2008) complicates the analysis even more. The best method has been a long-debated topic (e.g. Gould 1966, Somerton 1980, Watters and Hobday 1998, Katsanevakis et al. 2007, Packard 2012) but the vision that relative growth follows the allometric function (in the strict sense that the relationship between the two measured quantities fits well to a power law) has prevailed in literature. The most widely used method is that of Somerton (1980), in which the relative growth is assumed to follow a twophase power function and size at maturity is therefore estimated as the breakpoint in a two-segment regression applied to the log transformed data. This practice has been the object of criticism (Watters and Hobday 1998, Katsanevakis et al. 2007, Packard 2012), mainly because it requires several a priori assumptions that are not necessarily met but are rarely tested.

Platyxanthus crenulatus (Milne-Edwards 1879) belongs to Platyxanthidae, a family of large edible crabs endemic to South American coasts (Thoma et al. 2012). These are robust crabs, frequently found in crevices of intertidal and subtidal rocky bottoms of the southwestern Atlantic temperate coasts, from $23^{\circ}$ to $44^{\circ} \mathrm{S}$ (Boschi 1964). Their claws have marked heterochely and laterality (i.e. dimorphism between chelae and the tendency for them to appear on a particular side of the body), traits associated with shell-breaking feeding habits (Laitano et al. 2013). Due to their abundance, large size and diet, $P$. crenulatus presumably has an important ecological role as a predator in benthic communities, similar to that of other stone crabs such as the Mennipidae in the northwestern Atlantic Ocean (Gerhart and Bert 2008).

Here we describe post-settlement changes of male and female $P$. crenulatus (habitat use and colour patterns; size and sexual differences in relative growth) and estimate the size at sexual maturity on the basis of several reproductive and morphologic indicators. Additionally, we have taken this opportunity to compare the performance of alternative morphometric analyses appearing in literature, testing the consistency of their results within the framework of other ontogenic changes described here and the scarce previous information on the species biology.

\section{MATERIALS AND METHODS}

Samples were taken on a monthly basis in Mar del

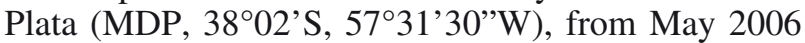
to April 2009, and sporadically during November 2007, April 2009 and January 2014 in San Antonio Oeste (SAO, 38 ${ }^{\circ} 53^{\prime} \mathrm{S}, 62^{\circ} 07^{\prime} \mathrm{W}$ ), Argentina (Fig. 1A). Mean water temperature ranges from $7.5^{\circ} \mathrm{C}$ in August (austral winter) to $20.6^{\circ} \mathrm{C}$ in January (australsummer) in MDP and from $4.4^{\circ} \mathrm{C}$ in August to $25.2^{\circ} \mathrm{C}$ in January in SAO (Servicio Argentino Hidrografia Naval, http:// www.hidro.gov.ar/). With few exceptions, samplings were carried out during daylight. Crabs were collected from 0 (intertidal sampling) to $20 \mathrm{~m}$ depth (subtidal sampling) on rocky and sandy bottoms. Subtidal samplings were performed on hard bottoms by SCUBA diving, on soft bottoms with a trawl net towed by a small outboard boat, and on intertidal flats simply by hand, turning small boulders and inspecting caves and crevices. External qualitative traits such as colour pattern and handedness (whether the crusher claw is carried at the right or left side of the body), and those clearly related to reproduction (namely egg-bearing and vulva condition) were observed and registered for each crab. Additionally, the following body dimensions (Fig. 2) were measured with a vernier caliper 


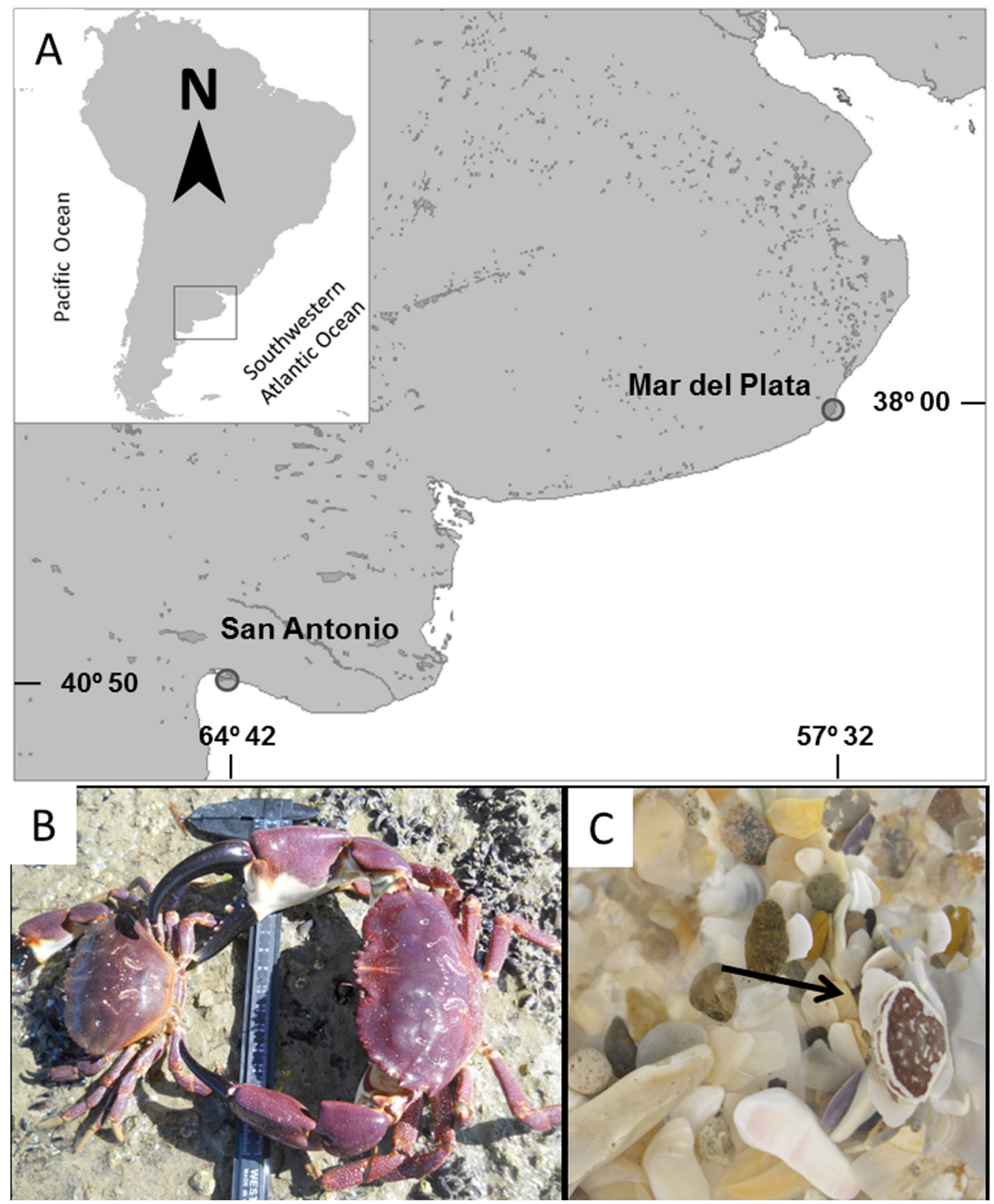

Fig. 1. - A, Sampling localities; B, members of a mating pair of Platyxanthus crenulatus (the smaller one is the female); C, a small juvenile showing the disruptive colour pattern against the broken shell bottom commonly found in intertidal pools.

with an accuracy of $0.1 \mathrm{~mm}$ : carapace length (CL) and width $(\mathrm{CW})$; length $(\mathrm{L})$, height $(\mathrm{H})$, and width $(\mathrm{W})$ of the propodus of the crusher $(\mathrm{Cr})$ and cutter $(\mathrm{Cu})$ chelae; gonopod length (GL) of males; and maximum width of the sixth abdominal segment of females (AW). Thus, a total of 11 and 13 measurements/observations of external features were recroded for each male and female, respectively. All statistical analyses (detailed below) were conducted using the $\mathrm{R}$ language for statistical computing (R Development Core Team 2011).

\section{Size-frequency distribution by habitat, sex and colour pattern}

After rejecting the hypothesis of differences between sites and among years, size data from all years and localities were pooled to produce larger carapace width $(\mathrm{CW})$-frequency distributions for each of the six possible combinations of sex and habitat type (intertidal, subtidal rocky bottom and subtidal soft bottom). Kernel density estimators (KDEs) were applied to each group, using the script in $\mathrm{R}$ provided in Langlois et al. (2012) slightly modified to our data. Briefly, KDEs are a non-parametric way to estimate the probability density function of a random variable. Then we tested habitat partitioning by size and sex by comparing the respective KDEs. The statistical method used to compare frequency distributions is sensitive to differences in both the shape of the distribution and its position on the horizontal axis (or in short form, the shape and site, respectively, Langlois et al. 2012). Therefore, to test for differences of shape alone, frequencies were also analysed standardized by median and variance ( $\mathrm{y}=\mathrm{x}-$ median/stdev). Histograms were made using $\mathrm{CW}$ 


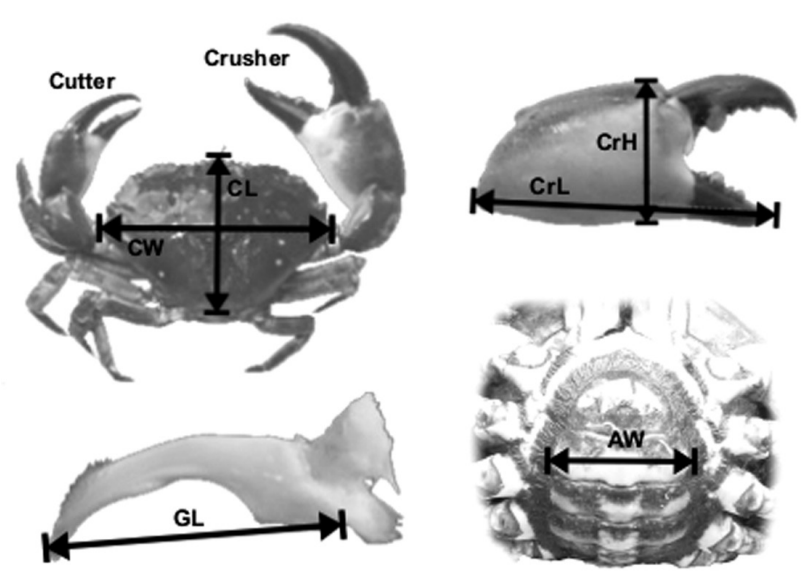

Fig. 2. - Body dimensions of Platyxanthus crenulatus measured for morphometric analysis. CW, carapace width; CL, carapace length; $\mathrm{CrL}$, length of the propodus of the crusher; $\mathrm{CrH}$, height of the propodus of the crusher; AW, maximum width of the sixth abdominal segment of females; GL, gonopod length

classes selected to best match the shape of the probability densities generated by the KDEs. Bandwidth of KDEs was chosen by the Sheather and Jones (1991) bandwidth selection procedure using the 'dpik' function in the 'KernSmooth' package (Wand 2013).

The colour pattern was classified on the basis of the dorsal part of the carapace, which may be either homogeneous purple or disruptive. Previous observation showed that the disruptive pattern is common among small individuals but absent in larger ones. Therefore, we studied the relationship between size and colour pattern by fitting a binomial model to the pooled data using the "glm()" function provided with the R base program.

\section{Relative growth and size at maturity calculated from morphometric indicators}

Morphometric data were log transformed and simple linear least-squares regressions were fitted with $\mathrm{CW}$ as the independent variable and the slope $b$ estimated for all log-log relationships. In order to detect sexual differences in relative growth, the slope $b$ was compared between males and females. Following Fernández-Vergaz (2000), body dimensions showing sexual differences in $b$ were considered secondary sexual features valid to be used to determine morphometric maturity. Claw data were analysed regardless of the crusher's laterality. Crabs were excluded from the analysis only when recent regeneration of chelae was evident by the presence of buds.

Once the body dimensions had been selected, morphometric maturity was calculated using two alternative methods: the traditional Somerton's method (Somerton 1980) and a smoothing spline-based method (slightly modified from Watters and Hobday 1998). Briefly, the Somerton's method consists of a predefined two-segment model which assumes that when a certain body part and CW are plotted against each other on a double logarithmic scale, the points lie along two straight lines. If the two-segment model fits significantly better than the simple linear model, then it is assumed that the first line describes the relative growth of juveniles and the second the relative growth of adults. This analysis was performed using the algorithm of the MATURE program described in Somerton (1980) and rewritten as a script in the $\mathrm{R}$ program.

The spline-based method consists of three steps. The first step is to bin the original data set (i.e. transform the original absolute size by replacing the original values which fall in a given small interval, technically a 'bin', by the mean value of that interval). Then, the measurements of the body part whose relative growth is under study are grouped in its respective bin (hereafter 'size class') and the median of each group is calculated, thus generating a paired data set with the mean size class as a predictor variable and the corresponding median of the body measure of interest as the response variable. The median was chosen instead of the mean to make the analysis robust to outliers on the response variable, particularly against the potential incorporation of small but well-developed claws, which are difficult to assign to a late stage of regeneration or to natural variation. The second step is to fit different spline models to these body size-specific medians and to choose the best spline, based on the trade-off between goodness of fit and smoothness (here the General Cross Validation criteria [GCV] was used). If the selected spline is significantly different from the straight line, the last step is to find the carapace size at which the second derivative of the fitted spline is maximized. The smoothing spline fitted to the morphometric data can be seen as the growth trajectory averaged for an individual lifespan. Thus, the first derivative of the fitted function is the instantaneous coefficient of relative growth, while the second derivative is the instantaneous rate of change for that coefficient. The point at which the second derivative of the fitted spline is maximized (i.e. the maximum rate of change in relative growth) is considered the size at morphometric maturity. On the other hand, when the second derivative of the fitted spline is equal to 0 , there is an inflection point in relative growth, and thus it changes from an increasing to a decreasing trajectory or vice versa. Unlike the traditional two-segment linear model (or any variant of segmented models), the spline's method has the advantage of not requiring a priori assumptions about the shape or the number of significant changes in relative growth rate during the ontogeny.

Both Somerton's method and the spline method were performed in the $\mathrm{R}$ program using scripts written for this specific purpose and are provided here as Appendix 1 .

\section{Size at maturity calculated from reproductive in- dicators}

Physiological maturity was assessed by macroscopic features of the respective female and male gonads as follows: 1) immature ovaries, small and barely visible as a translucent filament or opaque thin tubes; 2) mature ovaries, large and conspicuous, varying from soft, translucent or pale pink colour, to a swollen, violet to red colour, with visible oocytes inside; 3) immature 
testes, very thin, translucent white filaments, with vas deferens indistinguishable from testes to the naked eye; and 4) mature testes, conspicuously thicker than immature testes and white in colour, with vas deferens easily distinguishable from testes, translucent white, highly convoluted and swollen with visible granules inside; maturity was corroborated by the presence of spermatophores.

Sexual maturity from a morphological, behavioural and functional perspective was assessed in females on the basis of vulvae, seminal receptacles and the presence of embryos, respectively. Vulvae were classified as mature or immature on the basis of their external shape and size. The presence of sperm in seminal receptacles was used as evidence of copulation regardless of their fullness degree. Although mature seminal receptacles vary greatly in size depending on the amount of sperm loaded, they are always opaque white and very conspicuous, while immature seminal receptacles are distinctly smaller and translucent yellowish in colour. The relationship between each kind of maturity and the specific indicator used for its determination is summarized in Table 1.

Size at functional maturity of females was calculated simply as the mean $\mathrm{CW}$ of ovigerous individuals. The indicators occurring only once during the lifespan (first gonad maturity in both sexes and the acquisition of mature forms of spermathecae and vulvae in females) were analysed as binomial variables in order to calculate size at physiological maturity (both sexes) and morphological and behavioural maturity (females). The proportion of individuals classified as adults in each size interval was fitted to a logistic curve and size at maturity was estimated using the equation

$$
\mathrm{P}_{\mathrm{i}}=1 /\left(1+\exp \left(a-b \times \mathrm{CW}_{\mathrm{i}}\right)\right),
$$

where $\mathrm{P}_{\mathrm{i}}$ is the proportion of mature individuals at a certain carapace size class $\mathrm{CW}_{\mathrm{i}}$, with $a$ and $b$ as constants. When $\mathrm{P}_{\mathrm{i}}=0.5$ then $\mathrm{CW}_{\mathrm{i}}$ is the mean size at maturity $\left(\mathrm{CW}_{50 \%}\right)$.

\section{RESULTS}

\section{Size-frequency distribution by habitat, sex and colour pattern}

A total of 1018 crabs (501 males, 517 females) were captured, ranging from 5.17 to $95.63 \mathrm{~mm} \mathrm{CW}$. Carapace acquired the characteristic colour that led to the vernacular name of $P$. crenulatus as size increases, in both sexes. Dorsally, smaller individuals had a disruptive colour pattern, so they become cryptic against intertidal backgrounds while large crabs were homogeneously purple to violet (Fig. 1B, C). All crabs were ventrally white. The frequency of animals with a disruptive pattern falls abruptly and disappears completely at approximately $40 \mathrm{~mm} \mathrm{CW}$. The size to which $50 \%$ of individuals still have a disruptive pattern is $20 \mathrm{~mm} \mathrm{CW}$ (C.I.95\% 18-21 mm CW). Handedness was biased to the right in both sexes $(\mathrm{p}<0.001)$ but left-handed males were more frequent than females, $(11.48 \%$ of females and $20.29 \%$ of males, $\mathrm{p}<0.001)$.
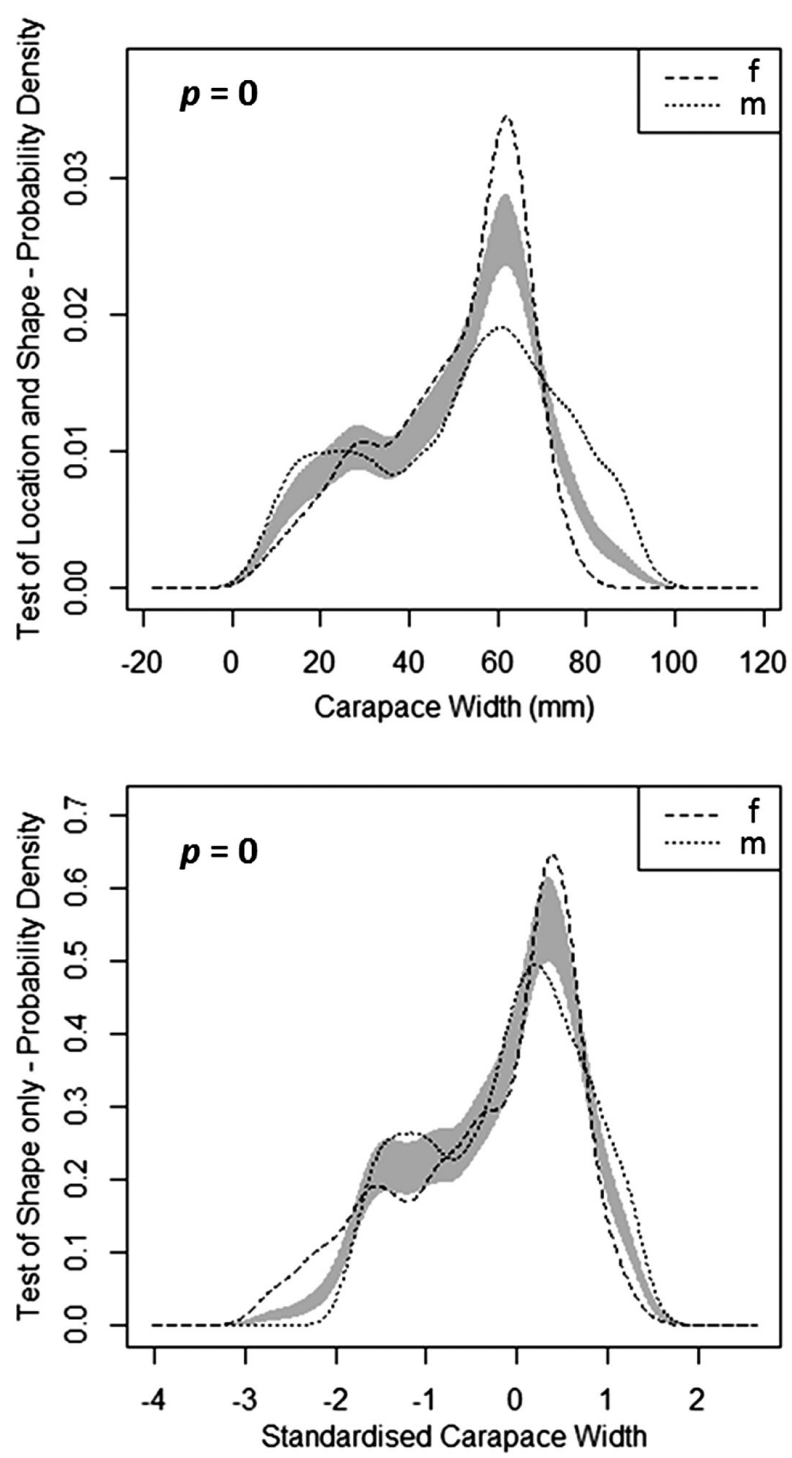

Fig. 3. - Sexual size dimorphism in Platyxanthus crenulatus. Comparison of kernel density estimate (KDE) probability density functions estimated for both sexes. Grey bands represent one standard error either side of the null model of no difference between the KDEs for each sex. Significance tests (p) were based on permutation tests of the area between the two probability density functions. Significance tests on raw data (top) provide a test of differences in both site and shape of the length-frequency distributions, whereas tests on standardized data (bottom) provide a test of shape only.

Overall sex ratio did not differ from $1: 1\left(\mathrm{Chi}_{\text {Yates }}=\right.$ $0.088, \mathrm{p}=0.767)$. There was sexual difference in both site and shape (sensu Langlois et al. 2012) of overall size-frequency distribution (KDE test for equal site and shape, $\mathrm{p}=0$; Fig. 3 ), with males reaching larger size than females. The largest male captured was $95.63 \mathrm{~mm}$ $\mathrm{CW}$, while the largest female was $81.46 \mathrm{~mm} \mathrm{CW}$.

Spatial distribution of $P$. crenulatus was clearly size-structured (Fig. 4). Small crabs were more frequent in intertidal and almost absent in subtidal samples, regardless of sex, while large crabs occupied mostly crevices and caves under large stones on subtidal rocky bottoms. On the intertidal flats, they were commonly found in patches of coralline algae and among pebble rocks and broken shells accumulated in the bottom of 

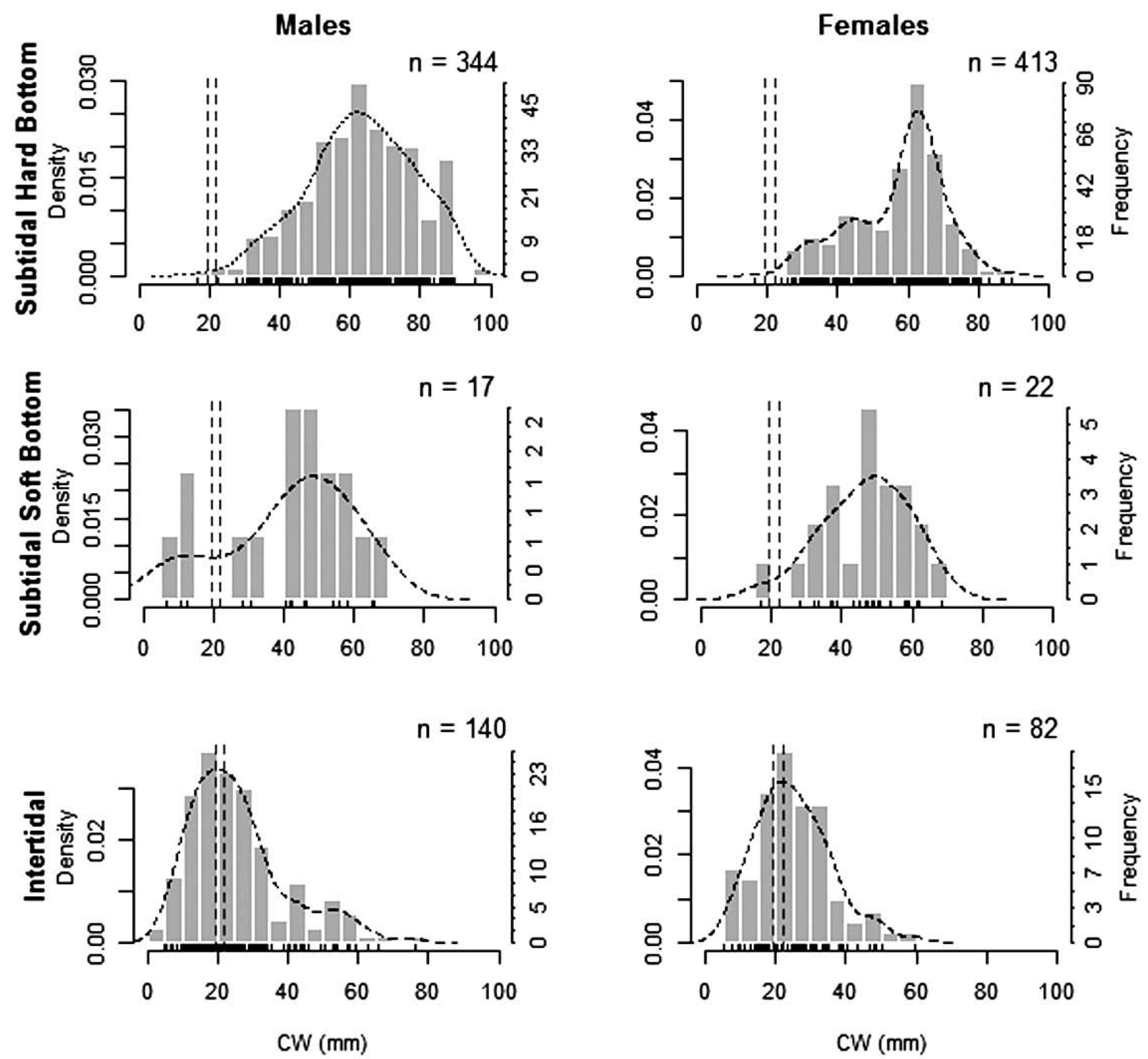

Fig. 4. - Size-frequency distribution of both sexes of Platyxanthus crenulatus sampled in different habitats. For the correspondent analysis the bandwidth of KDE was chosen by the Sheather and Jones (1991) bandwidth selection procedure. To facilitate visual comparisons, size classes on plots were all set to match the bandwidth for the males on subtidal hard bottom. Rug plot just above the $\mathrm{x}$-axis indicates individual observations. The two dashed vertical lines limit the confidence interval for $50 \%$ probability of change in colour pattern; ' $n$ ' indicates sample size.

pools. On subtidal soft bottoms the individuals were scarce and their sizes encompassed most of the range, except the largest sizes; the presence of smaller juveniles could not be detected there given the limitations of subtidal sampling.

\section{Relative growth and size at maturity calculated from morphometric indicators}

All body dimensions analysed showed sexual differences in allometric growth (Table 1). Both male and female chelae were positively allometric $(b>1)$, except the cutter claw of females. Among the relative growth constants of chelae, CrL of males had the smallest variance and the best fit to the simple linear model (see Table 1). Thus, if CrL differed from the linear pattern, the other dimensions of the chela must differ even more and therefore we chose $\mathrm{CrL}$ to determine male morphological maturity. We also used GL of males and AW of females since both are undoubtedly secondary sexual traits directly involved in reproduction.

In males, $\mathrm{CrL}$ was most appropriately modeled by a spline with $5 \mathrm{df}$ and $3 \mathrm{df}$ for males and females, respectively. The best spline for GL had $5 \mathrm{df}$, describing an asymptotic-like decreasing parabola; AW was better modeled by a 6 df spline describing an S-shaped curve (Fig. 5). The spline method determined a major change in male relative growth of $\mathrm{CrL}$ and GL at $59 \mathrm{~mm} \mathrm{CW}(95 \%$ C.I. $57-67 \mathrm{~mm}$ ) and $57 \mathrm{~mm} \mathrm{CW}$ (95\% C.I. 55-60 mm), respectively, indicating that at these sizes morphometric maturity occurs. The main change in growth rate of $\mathrm{CrL}$ and GL estimated by MATURE was at $66 \mathrm{~mm} \mathrm{CW}(95 \%$ C.I. $64-68 \mathrm{~mm}$ ) and $65 \mathrm{~mm}$ (95\% C.I. 63-67 mm), respectively (Table 2). In females, the spline method detected a change in the relative growth of the sixth abdominal segment width (AW) at $46 \mathrm{~mm} \mathrm{CW}$ (95\% C.I. $44-48 \mathrm{~mm})$ 
Table 1. - Allometric growth in Platyxanthus crenulatus. Estimated parameters for allometric equations (i.e. simple linear regressions applied to $\log$ - $\log$ transformed data) of different body parts of both sexes. Slopes are the "constants of relative growth" of each body part.

\begin{tabular}{|c|c|c|c|c|c|c|c|}
\hline Dimension & Parameter & value & sd & $\mathrm{t}$ & \multicolumn{2}{|c|}{ CW $95 \%$} & $\mathrm{r}^{2}$ \\
\hline \multirow{2}{*}{ Carapace length } & intercept & -0.07 & 0.01 & -13.97 & -0.08 & -0.06 & 1.00 \\
\hline & slope & 0.96 & 0.00 & 313.26 & 0.95 & 0.96 & \\
\hline \multirow{2}{*}{ 6th abdominal segment width } & intercept & -1.26 & 0.02 & -58.60 & -1.30 & -1.22 & 0.98 \\
\hline & slope & 1.44 & 0.01 & 112.29 & 1.42 & 1.47 & \\
\hline \multirow[b]{2}{*}{ Gonopod length } & intercept & -0.57 & 0.02 & -32.20 & -0.60 & -0.53 & 0.97 \\
\hline & slope & 0.95 & 0.01 & 93.55 & 0.93 & 0.97 & \\
\hline \multirow{2}{*}{ Female crusher length } & intercept & -0.33 & 0.02 & -16.58 & -0.37 & -0.29 & 0.98 \\
\hline & slope & 1.09 & 0.01 & 90.46 & 1.07 & 1.12 & \\
\hline \multirow{2}{*}{ Male crusher length } & intercept & -0.50 & 0.02 & -31.41 & -0.53 & -0.47 & 0.98 \\
\hline & slope & 1.23 & 0.01 & 130.30 & 1.21 & 1.25 & \\
\hline \multirow{2}{*}{ Female crusher width } & intercept & -0.72 & 0.03 & -27.79 & -0.77 & -0.67 & 0.96 \\
\hline & slope & 1.13 & 0.02 & 73.77 & 1.10 & 1.17 & \\
\hline \multirow{2}{*}{ Male crusher width } & intercept & -0.87 & 0.03 & -32.81 & -0.92 & -0.82 & 0.96 \\
\hline & slope & 1.25 & 0.02 & 80.35 & 1.22 & 1.28 & \\
\hline \multirow{2}{*}{ Female crusher height } & intercept & -0.82 & 0.03 & -25.11 & -0.88 & -0.76 & 0.94 \\
\hline & slope & 1.09 & 0.02 & 56.67 & 1.05 & 1.13 & \\
\hline \multirow{2}{*}{ Male crusher height } & intercept & -0.99 & 0.02 & -41.04 & -1.03 & -0.94 & 0.97 \\
\hline & slope & 1.22 & 0.01 & 87.05 & 1.19 & 1.25 & \\
\hline \multirow{2}{*}{ Female cutter length } & intercept & -0.26 & 0.02 & -13.23 & -0.30 & -0.22 & 0.97 \\
\hline & slope & 1.00 & 0.01 & 87.01 & 0.98 & 1.03 & \\
\hline \multirow{2}{*}{ Male cutter length } & intercept & -0.43 & 0.02 & -24.88 & -0.46 & -0.40 & 0.98 \\
\hline & slope & 1.12 & 0.01 & 110.93 & 1.10 & 1.14 & \\
\hline \multirow{2}{*}{ Female cutter width } & intercept & -0.60 & 0.02 & -24.70 & -0.65 & -0.55 & 0.96 \\
\hline & slope & 0.98 & 0.01 & 68.16 & 0.95 & 1.01 & \\
\hline \multirow{2}{*}{ Male cutter width } & intercept & -0.78 & 0.02 & -35.39 & -0.83 & -0.74 & 0.96 \\
\hline & slope & 1.11 & 0.01 & 85.54 & 1.08 & 1.13 & \\
\hline \multirow[b]{2}{*}{ Female cutter height } & intercept & -0.72 & 0.03 & -26.48 & -0.78 & -0.67 & 0.94 \\
\hline & slope & 0.96 & 0.02 & 59.79 & 0.93 & 0.99 & \\
\hline \multirow[b]{2}{*}{ Male cutter height } & intercept & -0.94 & 0.02 & -47.17 & -0.98 & -0.90 & 0.97 \\
\hline & slope & 1.11 & 0.01 & 95.88 & 1.09 & 1.13 & \\
\hline
\end{tabular}

Table 2. - Summary of statistics and estimated parameters of the simple linear model and two-phase linear model (Somerton's method fitted using the MATURE program) applied to the four morphometric characters used to estimate first maturity of both sexes of Platyxanthus crenulatus. SLM, simple linear model; SSE, sum of squared errors. Somerton's immature or juvenile (Juv) and mature (Mat) are the first and second segments of the two-phase linear model, respectively. CW, carapace width; CrL, length of the propodus of the crusher; AW, maximum width of the sixth abdominal segment of females; GL, gonopod length

\begin{tabular}{|c|c|c|c|c|}
\hline & CrL females & CrL males & AW & GL \\
\hline Max CW Juvenile known & 25 & 40 & 25 & 30 \\
\hline Min CW Mature known & 50 & 60 & 50 & 70 \\
\hline Intercep Juv Somerton's & -0.48 & -0.71 & -2.46 & -1.91 \\
\hline Slope Juv Somerton's & 1.00 & 1.09 & 1.28 & 1.13 \\
\hline Intercept Mat Somerton's & -0.84 & -2.55 & -2.86 & -0.67 \\
\hline Slope Mat Somerton's & 1.12 & 1.56 & 1.44 & 0.80 \\
\hline Intercept SLM & -0.76 & -1.16 & -2.91 & -1.31 \\
\hline Slope SLM & 1.09 & 1.23 & 1.44 & 0.95 \\
\hline SSE SLM & 0.57 & 1.75 & 2.80 & 0.99 \\
\hline SSE juv + mat Somerton's & 0.44 & 0.67 & 2.00 & 0.73 \\
\hline F statistic & 21.42 & 222.85 & 54.46 & 47.80 \\
\hline P Fobs & 0.00 & 0.00 & 0.00 & 0.00 \\
\hline CW 50\% & 52.12 & 65.98 & $\mathbf{5 8 . 5 5}$ & 65.10 \\
\hline Lower $95 \%$ limit & 49.92 & 64.42 & 56.66 & 63.40 \\
\hline Upper $95 \%$ limit & 54.31 & 67.97 & 59.40 & 66.73 \\
\hline
\end{tabular}

and MATURE yielded a change in growth rate at $58 \mathrm{~mm}$ CW (95\% C.I. 57-59 mm; Table 2).

Growth trajectories of male and female CrL (determined by splines) coincided during the first stages of the ontogeny. Relative growth of male's CrL rapidly increased when body size exceeded approximately 45 $\mathrm{mm} \mathrm{CW}$, initiating the conspicuous sexual dimorphism of chelae observed among large individuals (Fig. 6). Interestingly, such divergence in trajectories of relative growth also coincided with the maximum relative growth rate of females' crushers and an inconspicuous bump in the relative growth trajectory of males' crushers, as marked in Figure 6. Moreover, when both methods applied to male CrL data were compared (Fig. 7), a survey of the residuals also suggested the existence of a second breakpoint. Consequently, the relative increase in male crusher length could be divided into three phases. The first two differed in the rate of relative growth but both had a positive allometry, with roughly the same variability in relative growth of claws. The third phase had negative allometry and much more variation than the previous two (see Fig. 7).

\section{Size at maturity calculated from reproductive indicators}

The sizes of physiological maturity of females and males were $\mathrm{CW}_{50 \%}=48.96 \mathrm{~mm}(95 \%$ C.I. $45.29-51.89$ $\mathrm{mm})$ and $\mathrm{CW}_{50 \%}=35.23 \mathrm{~mm}(95 \%$ C.I. 33.39-37.28 $\mathrm{mm})$, respectively. The size of behavioural maturity calculated from the proportion of females with mature spermathecae (i.e. containing spermatophores despite 

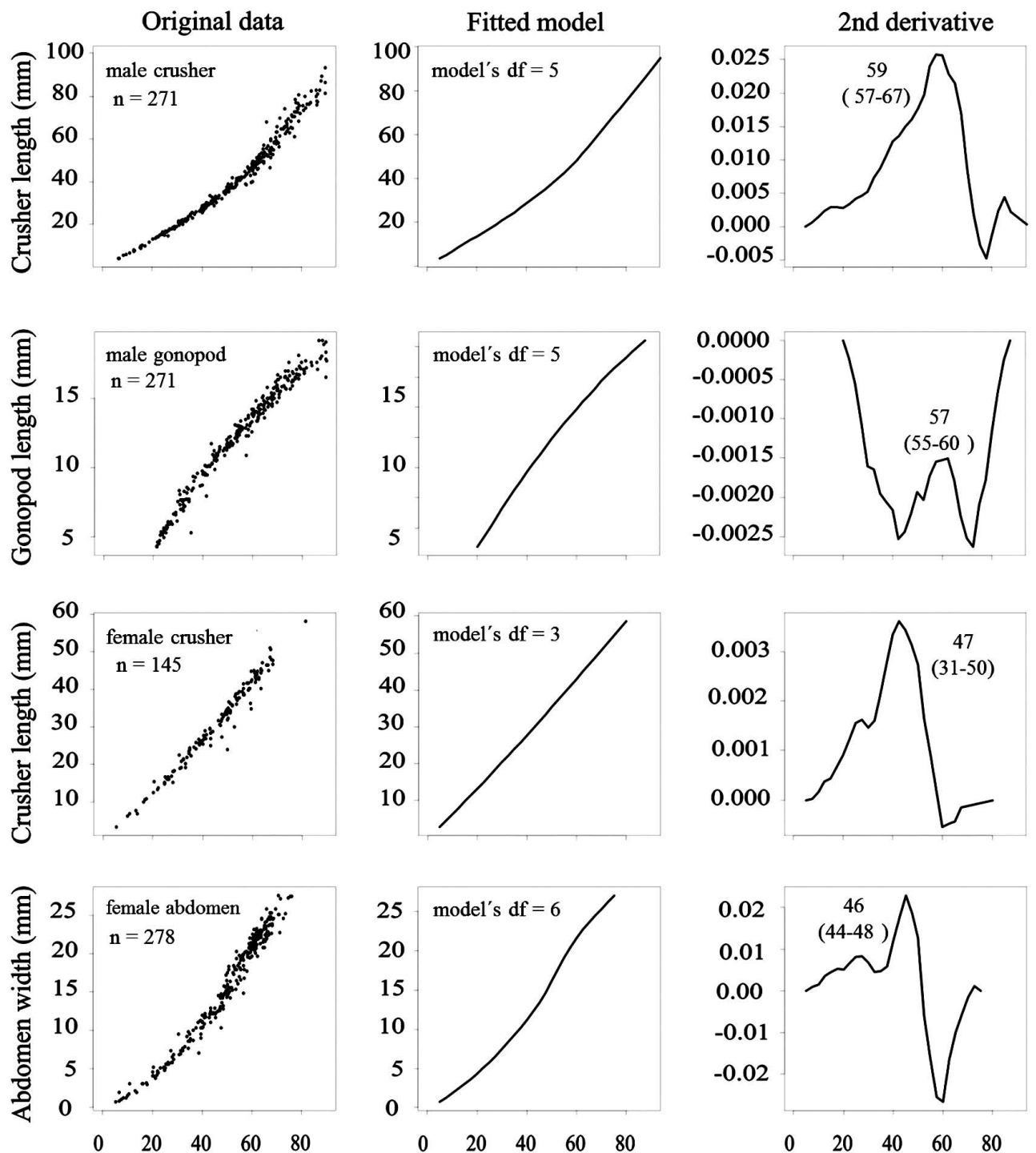

Fig. 5. - Relative growth and morphometric maturity of Platyxanthus crenulatus. Size at morphometric maturity as determined by the splines method (Watters and Hobday 1998) applied to morphometric data of selected measures of males and females. The most appropriate model was chosen according to the generalized cross-validation criterion (GCV). The peaks in the second derivative of the selected model are marked changes in relative growth that correspond to morphometric maturity.
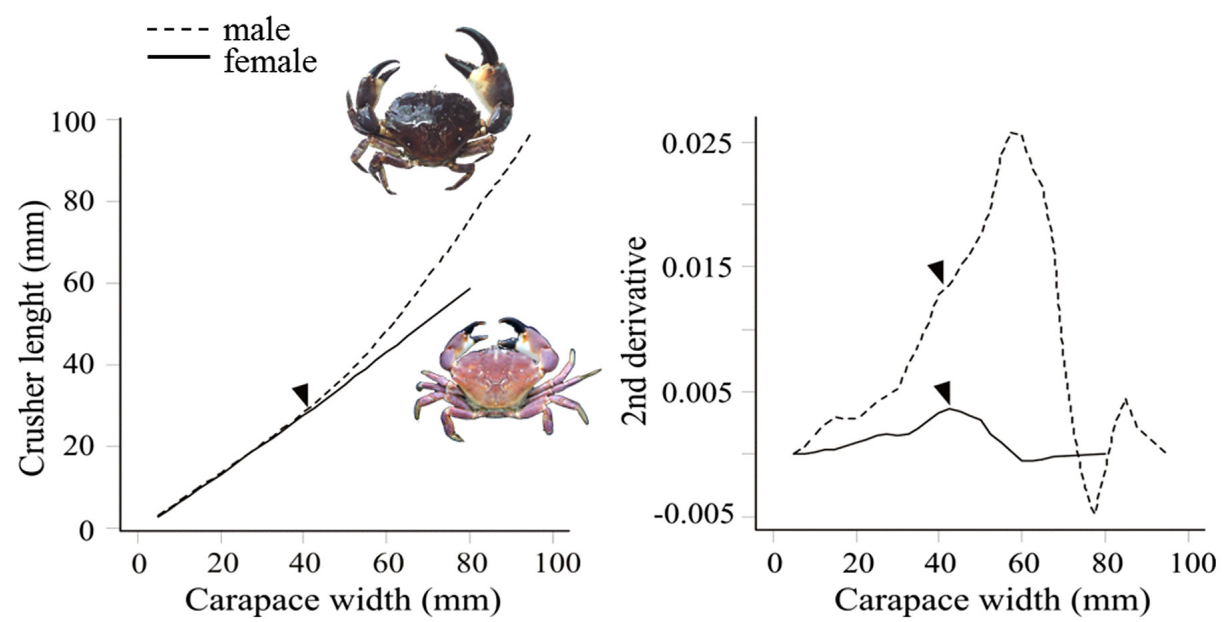

Fig. 6. - Sex differences in relative growth of the propodus length of the crusher chela of Platyxanthus crenulatus. Left: relative growth models estimated by the splines method and selected by general cross-validation; note the conspicuous crusher chela in the picture of the larger male. Right: the second derivative of the selected spline models. Males are in dotted lines and females in solid lines. Black arrows show the point at which relative growth rate diverges between sexes. 

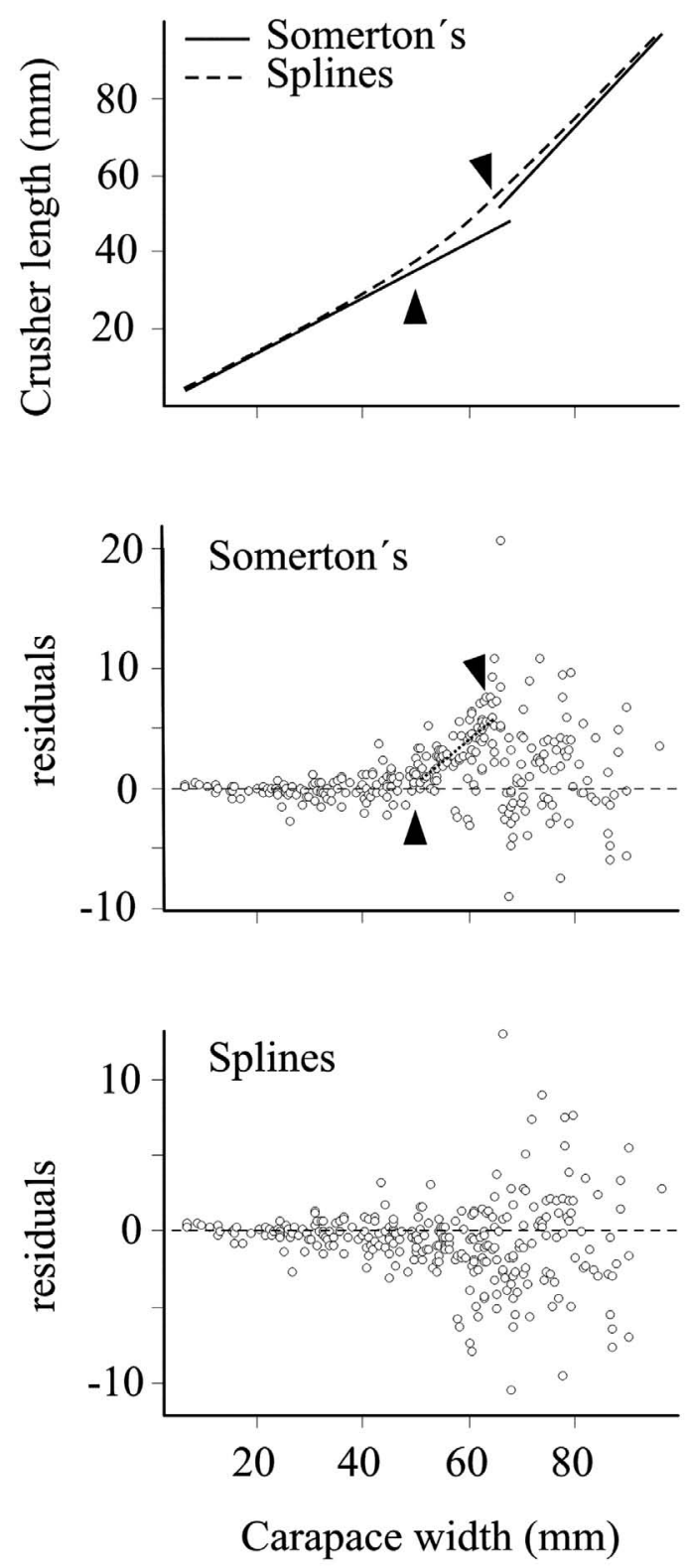

Fig. 7. - Top: the splines model and the Somerton's model applied to growth of the propodus length of the crusher chela $(\mathrm{CrL})$ in males of Platyxanthus crenulatus. Middle: residuals from Somerton's model. Bottom: residuals from splines. Note that Somerton's residuals can be divided into three well-defined moments (indicated by black arrows and the dotted line).

the volume of sperm loaded) was $\mathrm{CW}_{50 \%}=58.40 \mathrm{~mm}$ (95\% C.I. 55.21-61.59 mm). Most ovigerous females were found in San Antonio during November 2007 $(n=44)$, while strikingly few were found in Mar del Plata during the three years sampled $(n=8)$. The size of functional maturity calculated as the mean CW of ovigerous females was $61.98 \mathrm{~mm}$ (95\% C.I. 60.27-63.68 $\mathrm{mm}$ ). The smallest ovigerous female found was 42.13 $\mathrm{mm} \mathrm{CW}$. The size of morphological maturity based on vulvar condition was $\mathrm{CW}_{50 \%}=51.86 \mathrm{~mm}(95 \%$ C.I. 50$53 \mathrm{~mm}$ ). Unplanned observations of a few immature females that moult in aquaria showed that vulvae of female $P$. crenulatus passed from the immature to the mature form in a single moult. Vulvae of the mature form always have a mobile operculum that remained soft regardless of the carapace hardness. These results are summarized in Figure 8.

\section{DISCUSSION}

In considering our results it is necessary to bear in mind that the data come from two separate populations. This is particularly important for the analysis of relative growth given that exogenous factors (mainly the annual cumulative temperature and nutrition status) control the somatic growth (see Smith and Chang 2007 for a more in depth review) and therefore differing environmental conditions might result in differences in growth at all levels. However, tests for differences between these two populations performed previously to pool the data showed no significant differences. This fact is not surprising given that in this particular case the temperature regime is similar between sites (actually the annual temperature range in SAO encompasses that of MDP) and there are no reasons to think a priori that the nutritional conditions differ significantly between populations. Moreover, in decapods the temperature affects mostly the duration of the intermoult period rather than the size increment per moult (Smith and Chang 2007 and references therein) and therefore differences in temperature will impact the output of age-based models rather than size-based models such as those developed in this work.

There was, however, a considerable difference between MDP and SAO in the number of ovigerous females. The strikingly low number of ovigerous females found in MDP (eight ovigerous females in three years of monthly samples) has two possible explanations. Either the ovigerous females in MDP segregate from the other individuals (something that does not happened in SAO), perhaps because they perform reproductive migrations outside the sampling area or, more simply, because there is a bias in our sampling due to differences in catchability between sites. Subtidal sampling in MDP was performed mostly within the port, in the breakwaters that are built with medium to small, irregularly stacked boulders of orthoquartzite rock, thereby generating an intricate structure with many caves and hollows inaccessible to divers. On the other hand, hard bottoms in SAO are composed of large platforms of sedimentary rocks with countless cracks, hollows and crevices that provide good shelter but are shallow enough for the hidden animals to be within the reach of the human arm. Although we cannot rule out the segregation of ovigerous females outside the sampling area, considering the distinctive behaviour of the ovigerous female $P$. crenulatus, which tends to hide and remain immotile for long periods (NEF pers. obs.), we believe the most likely explanation is that the highly structured habitat in MDP prevented ovigerous females from being caught.

At a species level, Platyxanthus crenulatus has male-biased sexual size dimorphism, which is likely the rule among free-living brachyurans. The populations are spatially structured by size, suggesting the possibility of different ontogenic niches and a migration of smaller individuals to deeper areas during growth. 


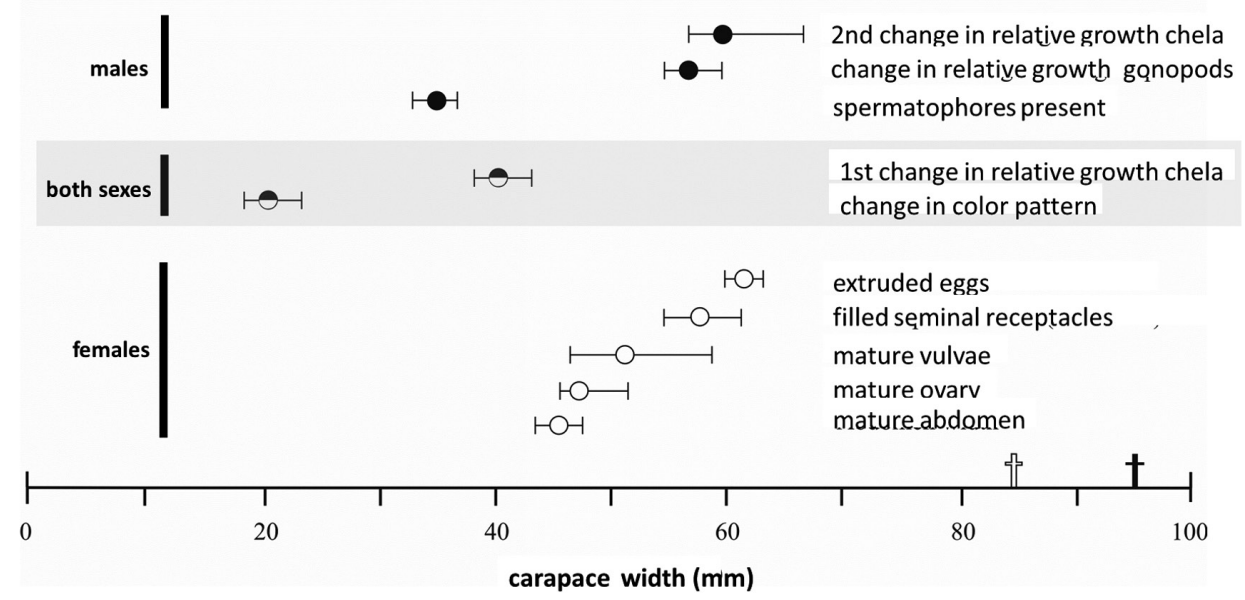

Fig. 8. - Graphic summary of noteworthy events of the post-settlement phase of male and female Platyxanthus crenulatus. Size of primiparous females is shown as mean value; size at gonad first maturity and spermathecae and vulvae maturation are $\mathrm{CW}_{50 \%}$ determined by the logit function fitted to the proportion of individuals having the mature version of the respective maturity indicator. Horizontal bars correspond to $95 \%$ CI for each event.

The species is clearly associated with hard substrates, as shown by the relatively small number of individuals found on sandy bottoms, which were likely roaming among the rocky outcrops scattered in the area. Changes in colour pattern accompany the ontogenic habitat shifting (see Fig. 1B, C), perhaps as an adaptation to the different colour backgrounds, diet and/or predator features that individuals would find while growing and moving to deeper waters.

In relation to the relative growth, the use of a nonpre-defined model revealed morphological changes that would also be involved in size-dependent use of habitat. Although slight in males, the first recognizable change in relative growth rate of chelae (shared by both sexes, see Fig. 6), may be an adaptive response to changes in feeding habits, intraspecific agonisms and/ or new predatory risks that might require a different claw shape and relative size. A similar relative growth pattern was described for the chelae of male stone crabs of the genus Menippe. In those crabs the first change in relative growth is also shared by both sexes, occurring at $35 \mathrm{~mm}$, and is considered to be an adaptive response to habitat shifting at that size (Gerhart and Bert 2008). As observed in P. crenulatus during this study, other stone crabs (e.g. Reuschel and Schubart 2007, Manríquez et al. 2008, Krause-Nehring et al. 2010) showed an early habitat shift that was also accompanied by loss or acquisition of cryptic colouration to fit the new environment.

The spline method showed that the relative growth rate of male gonopods decreased gradually while body size increased. Since there is positive correlation between gonopod length and width (NEF, unpublished data), this growth pattern may be explained simply by the trade-off between the total body growth and the limitations imposed by the size of the mature vulvae of females, as stated by Hartnoll (1974). In P. crenulatus the vulvae underwent an abrupt change in size and shape at a body size that coincided with the size at maturity estimated from the abdomen width by the spline method (Fig. 8). Instead of the two linear segments to which the traditional method is restricted, the spline method applied to females' abdomen showed a rather sigmoid growth pattern (Fig. 5). The sigmoid shape of the growth trajectory is consistent with the expected compromise between the need to expand the abdomen to accommodate as many embryos as possible in order to increase fertility against the restriction imposed by the female sternum width (Hartnoll 1974). Interestingly, in species in which females have determinate growth and terminal moult, a model with two discontinuous phases with different levels of allometry (as defined by the traditional method) seems to fit better the relative growth of female abdomen (e.g. Sainte-Marie and Brêthes 1995, Sampedro et al. 1999). In contrast, in brachyurans with indeterminate growth such as those studied here, an S-shaped model seems to describe the relative growth best (e.g. Luppi et al. 2004, Katsanevakis et al. 2007, this work).

Our results on the attainment of sexual maturity of $P$. crenulatus revealed the following sequence of maturation in females. First, relative growth of the abdomen reached its maximum (i.e. it will continue growing afterwards but at a lower rate). Later, while the abdomen grew through successive molts, the ovary matured to the point that the vulva changed to its mature form in a single moult, and the abdomen became broad enough to accommodate the egg clutch. When the female had reached sexual maturity, the vulva remained soft, independently of the moult cycle. In turn, physiological maturity precedes morphological maturity in male $P$. crenulatus and both are lastly followed by behavioural maturity. This pattern is shared by other brachyurans (Watters and Hobday 1998), although in some species such as Chaceon affinis A. Milne-Edwards and Bouvier, 1894 the onset of the different maturity stages is fairly synchronized (Fernández-Vergaz et al. 2000).

This study illustrates the advantages of studying relative growth in a comprehensive manner, using methods that do not rely on previous assumptions. Such an approach may provide further information useful for generating new hypotheses on life history and mating strategies, thus leading future research on the species beyond the mere size at onset of maturity. 
Whereas conspicuous changes in the morphology of female abdomens and vulvae, and male gonopods, are undoubtedly related to the maturation process, this is not necessarily the case for the chelae. The high predominance of right-handed individuals (those carrying a crusher claw at the right side) in both sexes suggests that natural selection may influence the size and shape of the chelae to fit the durophagous habits (Laitano et al. 2013) as much as sexual selection may enhance the ability to mate. Changes in relative growth are consistent with this hypothesis. Morphometric maturity of males, calculated by the spline method applied to the crusher claw, did not differ significantly from that using the gonopod length. Unexpectedly, spermatophores were present in very small males (physiological maturity 33-37 $\mathrm{mm} \mathrm{CW}$ ) long before their gonopods were morphometrically mature $(55-60 \mathrm{~mm} \mathrm{CW})$ and also before females developed oocytes for the first time and acquired the open mature form of the vulva that allows gonopod penetration. If small males (i.e. ones that are physiologically mature but morphologically immature) have spermatophores, one might expect them to be able to mate with females larger than themselves, at least in absence of competition with other males, as reported in some other crabs (e.g. Wilber 1989, Sainte-Marie and Lovrich 1994, Gerhart and Bert 2008). This is an interesting idea for future testing under experimental conditions, given the implications regarding mating strategies and the socio-spatial structure of the populations.

\section{ACKNOWLEDGEMENTS}

This work is part of the PhD thesis of NEF supported by a fellowship of the Consejo Nacional de Investigaciones Científicas y Técnicas (CONICET). The field work and sampling was partially supported by funds of CONICET (PIP 112-200801-00176) and Universidad Nacional de Mar del Plata (UNMdP: EXA517 /10) granted to EDS. NEF is especially grateful for the support of the PADI foundation, which provided the necessary funds for field work. Finally, we want to sincerely thank the anonymous reviewers, whose feedback greatly improved this manuscript.

\section{REFERENCES}

Boschi E.E. 1964. Los crustáceos decápodos Brachyura del litoral boanaerense. Bol. Inst. Biol. Mar. 6: 1-76.

Fernández-Vergaz V., Abellán L.J.L., Balguerías E. 2000. Morphometric, functional and sexual maturity of the deep-sea red crab Chaceon affinis inhabiting Canary Island waters: chronology of maturation. Mar. Ecol. Prog. Ser. 204: 169-178. http://dx.doi.org/10.3354/meps204169

Gerhart S.D., Bert T.M. 2008. Life-history Aspects of Stone Crabs (Genus Menippe): Size at Maturity, Growth, and Age. J. Crustac. Biol. 28: 252-261. http://dx.doi.org/10.1651/0278-0372(2008)028[0252:LAOSC $\mathrm{G}] 2.0 . \mathrm{CO} ; 2$

Gould S.J. 1966. Allometry and size in ontogeny and phylogeny. Biol. Rev. Camb. Philos. Soc. 41: 587-640. http://dx.doi.org/10.1111/j.1469-185X.1966.tb01624.x

Hall N.G., Smith K.D., de Lestang S., et al. 2006. Does the largest chela of the males of three crab species undergo an allometric change that can be used to determine morphometric maturity? ICES J. Mar. Sci. 63: 140:150.

Hartnoll R.G. 1974. Variation in growth pattern between some secondary sexual characters in crabs (Decapoda Brachyura).
Crustaceana 27: 131-136.

http://dx.doi.org/10.1163/156854074X00334

Jensen G.C., Asplen M.K. 1998. Omnivory in the diet of juvenile dungeness crab, Cancer magister Dana. J. Exp. Mar. Bio. Ecol. 226: $175-182$

http://dx.doi.org/10.1016/S0022-0981(97)00244-X

Katsanevakis S., Thessalou-Legaki M., Karlou-Riga C., et al. 2007. Information-theory approach to allometric growth of marine organisms. Mar. Biol. 151: 949-959. http://dx.doi.org/10.1007/s00227-006-0529-4

Krause-Nehring, J., Starck, M., Palmer, R. A. 2010. Juvenile colour polymorphism in the red rock crab, Cancer productus: patterns, causes, and possible adaptive significance. Zoology, 113(3): 131-139. http://dx.doi.org/10.1016/j.zool.2009.09.002

Laitano M.V., Farias N.E., Cledón M. 2013. Prey preference of the stone crab Platyxanthus crenulatus (Decapoda: Platyxanthidae) in laboratory conditions. Nauplius 21: 17-23. http://dx.doi.org/10.1590/S0104-64972013000100003

Langlois T.J., Fitzpatrick B.R., Fairclough D.V., et al 2012. Similarities between line fishing and baited stereo-video estimations of length-frequency: novel application of Kernel Density Estimates. PloS One 7: e45973. http://dx.doi.org/10.1371/journal.pone.0045973

Leal G.A., Dima J.B., Dellatorre F.G., et al. 2008. Schedule of reproductive events and maturity at size of the Patagonian stone crab Platyxanthus patagonicus (Brachyura, Platyxanthidae). J. Crustac. Biol. 28: 262-269. http://dx.doi.org/10.1163/20021975-99990373

López-Greco L.S., Rodríguez E.M. 1999. Size at the onset of sexual maturity in Chasmagnatus granulata Dana, 1851 (Grapsidae, Sesarminae): a critical overall view about the usual criteria for its determination. In: Schram F.R., Klein J.C. von V. (eds), Crustacean and the Biodiversity Crisis, Fourth Int. Crustac. Congr. Brill, Amsterdam, Leiben, pp 675-679.

Luppi T.A., Spivak E.D., Bas C.C., et al. 2004. Molt and growth of an estuarine crab, Chasmagnathus granulatus (Brachyura: Varunidae), in Mar Chiquita coastal lagoon, Argentina. J. Appl. Ichthyol. 20: 333-344. http://dx.doi.org/10.1111/j.1439-0426.2004.00575.x

Manríquez K. C., Pardo, L. M., Wells, R. J. D., et al. 2008. Crypsis in Paraxanthus barbiger (Decapoda: Brachyura): Mechanisms against visual predators. J. Crustac. Biol. 28(3): 473-479. http://dx.doi.org/10.1651/07-2893R.1

Packard G.C. 2012. Julian Huxley, Uca pugnax and the allometric method. J. Exp. Biol. 215: 569-573. http://dx.doi.org/10.1242/jeb.061739

Palma A.T, Steneck R.S. 2001. Does variable coloration in juvenile marine crabs reduce risk of visual predation? Ecology 82: 2961-2967. http://dx.doi.org/10.1890/0012-9658(2001)082[2961:DVCIJM 12.0. $\mathrm{CO} ; 2$

Pardo L.M., Palma A.T., Prieto C., et al. 2007. Processes regulating early post-settlement habitat use in a subtidal assemblage of brachyuran decapods. J. Exp. Mar. Biol. Ecol. 344: 10-22. http://dx.doi.org/10.1016/j.jembe.2006.12.024

R Development Core Team. 2011. R: A language and environment for statistical computing.

Reuschel S., Schubart C.D. 2007. Contrasting genetic diversity with phenotypic diversity in coloration and size in Xantho poressa (Brachyura: Xanthidae), with new results on its ecology. Mar. Ecol. 28: 296-305. http://dx.doi.org/10.1111/j.1439-0485.2006.00139.x

Sainte-Marie B., Brêthes J-C. 1995. Growth and maturation of the benthic stages of male snow crab, Chionoecetes opilio (Brachyura: Majidae). Can. J. Fish. Aquat. Sci. 52: 903-924. http://dx.doi.org/10.1139/f95-091

Sainte-Marie B., Lovrich G.A. 1994. Delivery and storage of sperm at first mating of female Chionoecetes opilio (Brachyura: Majidae) in relation to size and morphometric maturity of male parent. J. Crustac. Biol. 14: 508-521. http://dx.doi.org/10.2307/1548997

Sal Moyano M.P., Gavio M.A., Maggi M.D. 2010. Morphometric and gonad maturity of the spider crab Libinia spinosa (Crustacea: Brachyura: Majoidea: Epialtidae) in Argentina. J. Mar. Biol. Assoc. U.K. 91(4): 837-844 http://dx.doi.org/10.1017/S0025315410001657

Sampedro M.P., González-Gurriarán E., Freire J., et al. 1999. Morphometry and sexual maturity in the spider crab Maja squinado (Decapoda: Majidae) in Galicia, Spain. J. Crustac. Biol. 19: 578-592. 
http://dx.doi.org/10.2307/1549263

Sheather S., Jones M. 1991. A reliable data-based bandwidth selection method for kernel density estimation. J. R. Stat. Soc. Ser. B 53: 683-690.

Shuster S.M. 2008. The expression of crustacean mating strategies. In: Oliveira RF, Taborsky M, Brockmann JH (eds), Alternative Reproductive Tactics: An Integrative Approach. Cambridge University Press, Cambridge, pp. 224-250. http://dx.doi.org/10.1017/CBO9780511542602.010

Smith S. G., Chang E. S. 2007. Molting and growth. In: Kennedy V.S., Cronin L.E. (eds), The blue crab Callinectes sapidus. Maryland Sea Grant College, Maryland, USA.

Somerton D.A. 1980. A computer technique for estimating the size of sexual maturity in crabs. Can. J. Fish. Aquat. Sci. 37: 1488-1494. http://dx.doi.org/10.1139/f80-192

Thoma B.P., Ng P.K., Felder D. 2012. Review of the family Platyxanthidae Guinot, 1977 (Crustacea, Decapoda, Brachyura, Eriphioidea), with the description of a new genus and a key to genera and species. Zootaxa 23: 1-23.

Wand M. 2013. KernSmooth: Functions for kernel smoothing for Wand and Jones (1995).

Watters G., Hobday A.J. 1998. A new method for estimating the morphometric size at maturity of crabs. Can. J. Fish. Aquat. Sci. 55: 704-714. http://dx.doi.org/10.1139/f97-266

Wilber D.H. 1989. Reproductive biology and distribution of stone crabs (Xanthidae, Menippe) in the hybrid zone on the northeastern Gulf of Mexico. Mar. Ecol. Prog. Ser. 52: 235-244. http://dx.doi.org/10.3354/meps052235

Appendix 1. - Script based on R commands (R Development Core Team 2011) used to study morphometric growth in male and female $P$. crenulatus by fitting smoothing splines. The carapace length where the second derivative of the best spline is maximized estimates the size at morphometric maturity (SAMM). The method is explained in the main text and in greater depth in Watters and Hobday (1998).

$$
\begin{aligned}
& \text { \#Load packages } \\
& \text { require(pspline) } \\
& \text { require(boot) }
\end{aligned}
$$

\#Load original dataset

orig<- read.table("C: :loriginaldataset.txt", header=T)

bin<- read.table("C: (lbinneddataset.txt", header=T)

\# Define objects from binned dataset

\# $x$ : independent variable; $y$ : dependent variable; $w$ : weights

$\mathrm{x}<-$ bin\$bin

$\mathrm{y}<-$ bin\$median

$\mathrm{w}<-$ bin $\$ \mathrm{w}$

\# Set 6 graphs as the number to be shown in the graphic device $\operatorname{par}(\mathrm{mfrow}=\mathrm{c}(2,3))$

\# Plot original data plot(orig,main="original data",xlab="CW(mm)",ylab="allometricdimention")

\# Determines the best model by General Cross Validation criteria $(G C V)$ and shows the correspondent parameters $\mathrm{GCV}<-\mathrm{c}()$ for(i in 2:12) GCV<-append(GCV,smooth.spline $(\mathrm{x}, \mathrm{y}, \mathrm{df}=\mathrm{i}$,penalty=2)\$cv.crit)

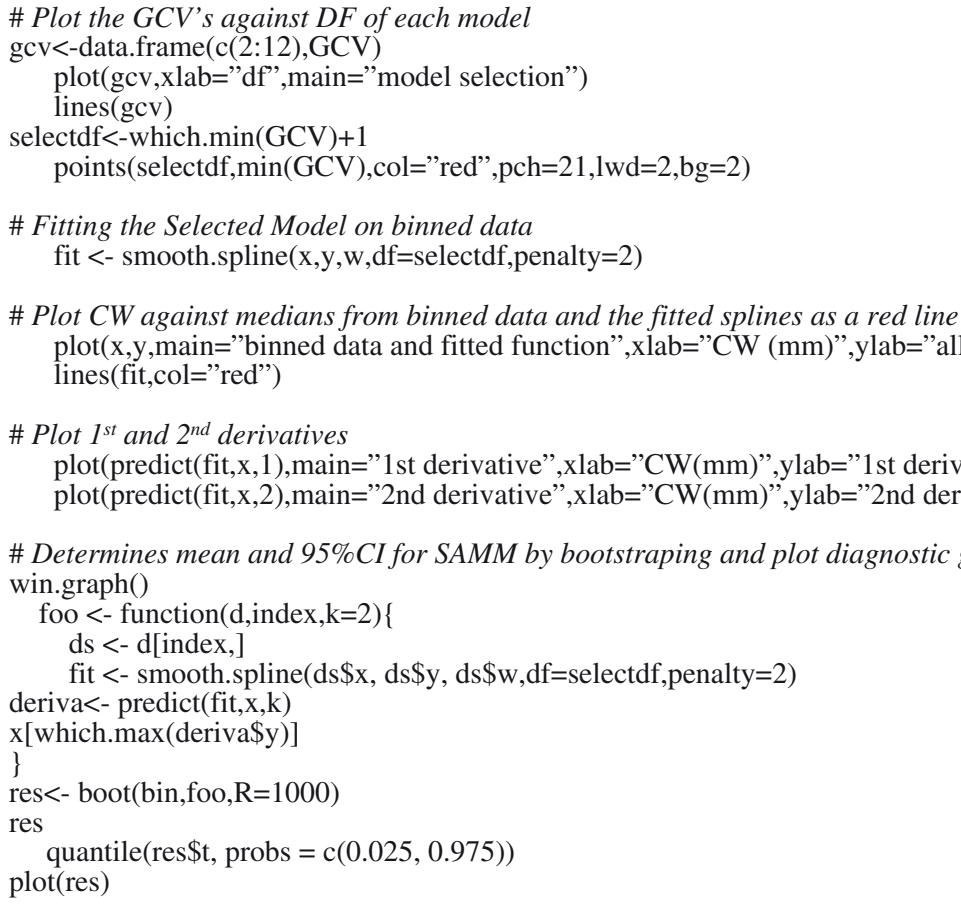

\# Fitting the Selected Model on binned data fit $<-$ smooth.spline $(x, y, w, d f=$ selectdf,penalty $=2)$

\# Plot CW against medians from binned data and the fitted splines as a red line lines(fit,col="red")

\# Plot $1^{\text {st }}$ and $2^{\text {nd }}$ derivatives win.graph()

foo $<-$ function $(\mathrm{d}$, index, $\mathrm{k}=2)\{$
$\mathrm{ds}<-\mathrm{d}[$ index,

fit <- smooth.spline $(\mathrm{ds} \$ \mathrm{x}, \mathrm{ds} \$ \mathrm{y}, \mathrm{ds} \$ \mathrm{w}, \mathrm{df}=$ selectdf,penalty $=2)$

deriva $<-\operatorname{predict}($ fit, $\mathrm{x}, \mathrm{k})$

$\mathrm{x}$ [which.max (deriva\$y)]

res<- boot(bin,foo, $\mathrm{R}=1000$ )

res

quantile $($ res $\$$ t, probs $=\mathrm{c}(0.025,0.975))$

plot(res) plot(x,y,main="binned data and fitted function",xlab="CW (mm)",ylab="allometricdimention") plot(predict(fit,x,1),main="1st derivative",xlab="CW(mm)",ylab="1st derivative",type="l",col="red" ) plot(predict(fit,x,2),main="2nd derivative",xlab="CW(mm)",ylab="2nd derivative",type="l",col="blue")

\# Determines mean and 95\% CI for SAMM by bootstraping and plot diagnostic graphs 